\title{
Servitized manufacture: Practical challenges of delivering integrated products and services
}

\begin{abstract}
Servitization is now widely recognised as the process of creating value by adding services to products. Since this term was first coined in the late 1980s, it has been studied by a range of authors seeking to understand the wider implications of service-led competitive strategies in manufacturing. Yet to be explored, however, are the detailed practices and processes needed to deliver integrated products and services. Therefore, the purpose of this paper is to illustrate the form of a real-life servitization process model, and to summarise the key challenges that a typical manufacturer experiences in supporting such a model. Our work is based on an in-depth case study with a leading provider of industrial products and related services. The paper presents this study, an illustration of their servitized process model, and the implications that supporting this model has on the wider manufacturing enterprise.
\end{abstract}

\section{Keywords:}

Manufacturing, products, service, servitization, model, case-study

\section{INTRODUCTION}

All manufacturers offer services, but some use services as the basis of their competitive strategy. Servitization is now widely recognised as the innovation of an organisation's capabilities and processes. It is used to better create mutual value, through a shift from selling product to selling Product-Service Systems (Baines et al, 2007; Aurich et al, 2007). Since this term was first coined, servitization has been studied by a range of authors (e.g. Wise \& Baumgartner, 1999; Oliva \& Kallenberg, 2003; Slack, 2005) who have specifically sought to understand the methods and implications of service-led competitive strategies for manufacturers. In addition, and somewhat independently during this same period, there has been a growth in research on the related topics of Product-Service Systems (PSS), Services-Science (SS) and Integrated Vehicle Health Management (IVHM). Traditionally, PSS research has sought to promote adoption of service based business models as a means to achieve environmental sustainability (Baines et al, 2007). Conversely, SS (Chesbrough and Spohrer, 2006) can be thought of as a research agenda, promoted by IBM in particular, with the purpose of understanding how to deliver complex services effectively and efficiently. Finally, IVHM focuses on the technology systems to monitor, diagnose and react to the performance of equipment in the field. IVHM is of particular interest to the larger aerospace organisations, such as the Boeing Company, who see such capabilities as key to exploiting future business opportunities.

This increasing body of research indicates a growing interest in this topic by academia, business and government. One reason for this is the belief that a move towards servitized manufacture is a means to create additional value-adding capabilities for traditional manufactures. Furthermore, such services are distinctive, long-lived, and easier to defend from competition based in lower cost economies. Indeed, many governments see such moves downstream as key to competitiveness (see Hewitt, 2002;4). As a 
consequence, more and more western manufacturers are seeking ever increasing percentages of their revenues from services (Wise \& Baumgartner 1999). However, there is some concern that servitized manufacturers are in greater danger of bankruptcy and make lower returns in the longer-term (Neely, 2007). Nevertheless, it is difficult to argue against a careful adoption of some services in some situations.

To succeed with servitization, a manufacturer is likely to need some new and alternative organisational principles, structures and processes (Oliva \& Kallenberg, 2003). These may be different to those associated with traditionally product manufacture. For example, it may be insufficient to simply attempt to replicate the lean principles of Toyota. This is an area of some contention amongst scholars as the adoption of lean is often seen as the solution to tackling the poorer performers in the services sector. While this may be appropriate in some instances, authors such as Chase (1989) argue strongly for reversing the trend of applying operational management based concepts in the services environment. They suggest that there is a subtle mix of organisational structures that are appropriate to a servitized manufacturer that are distinct and different to those associated with, either a more traditional product manufacture, or a pure service provider. However, researchers have yet to describe the particular challenges that manufacturers encounter when attempting to deliver both products and services. This therefore is the purpose of this paper.

This paper has set out to present the implications, on a typical manufacturer, of adopting a servitization process model. This has largely been based on a study of a leading provider of integrated products and services. The targeted company (which we refer to under the pseudonym of ServCase) is a large manufacturer that now generates a large proportion of its revenue from product-centric service contracts (i.e.: services that are tightly coupled to the product offering). Our research with ServCase has helped us to appreciate how servitization impacts many aspects of manufacturing, ranging from the 'language' used during customer interactions, through to change management issues. The background to this study, our research design and subsequent findings, are all presented in this paper.

\section{OVERVIEW OF PREVIOUS RESEARCH}

The first use of the term servitization came from Vandemerwe and Rada (2008) in their article in the European Management Journal titled 'Adding Value by Adding Services'. Here they defined 'the servitization of business' as the increased offering of fuller market packages or 'bundles' of customer focussed combinations of goods, services, support, self-service and knowledge in order to add value to core corporate offerings. Rightly or wrongly, the terms service and product (goods) are intrinsically linked to discussions about servitization. The term 'product' is generally well understood by manufacturers. As Goedkoop (1999) defines, a product is a tangible commodity manufactured to be sold and, quite simplistically, is capable of 'falling on your toe' and of fulfilling a user's needs. Invariably, in the world of manufacture, it is usually considered to be a material artefact (e.g. car, boat, plane). Consequently, we will consider that services are an economic activity that does not result in ownership of a tangible asset. 


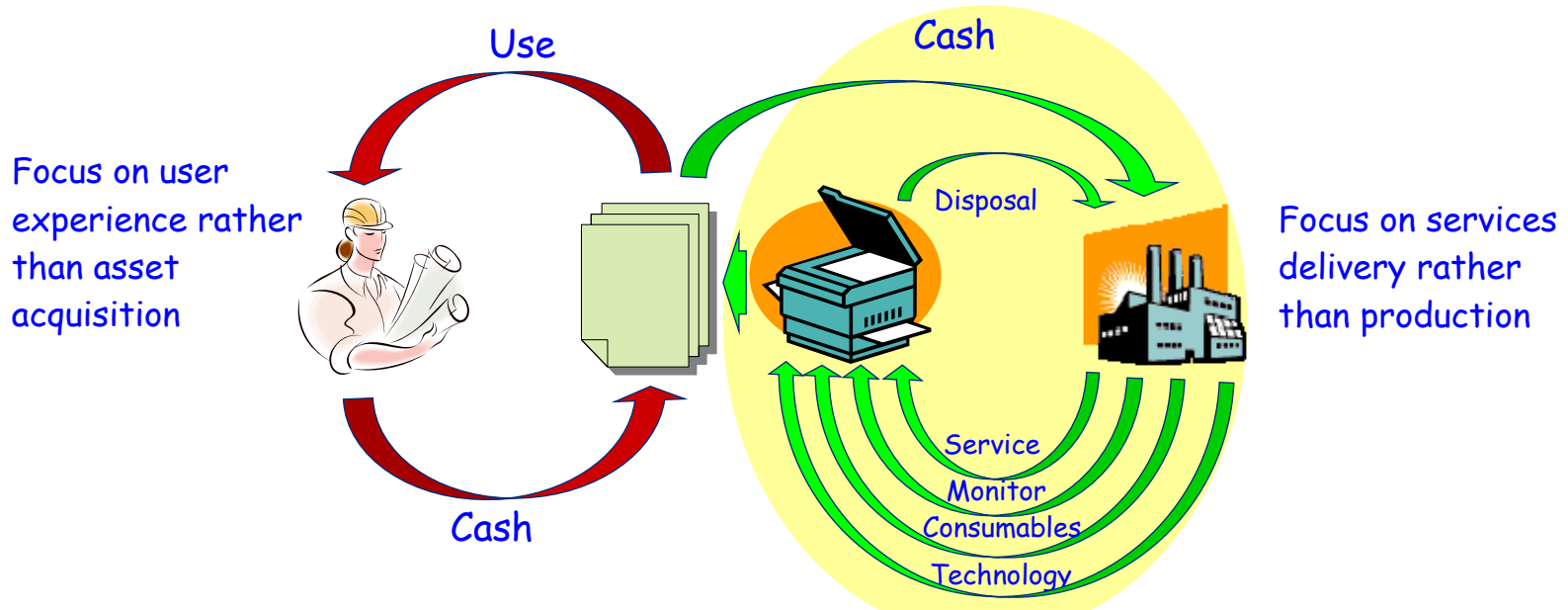

Figure 1: Schematic example of a customer purchasing a solution rather than asset (see Baines et al, 2007)

Servitization is the move from selling products to selling Product Service-Systems (PSSs) (Baines et al, 2007). Though different authors use different labels and different sub-divisions to describe PSS forms, there is some convergence on the existence of three different PSS types, namely; product-oriented PSS (promoting/selling the product in a traditional manner while including additional services as part of the offering); use-oriented PSS (selling the use or availability of a product which is not owned by the customer such as leasing or sharing); and result-oriented PSS (selling a result or capability instead of a product, such as selling laundered clothes instead of a washing machine). Generally, a PSS can be thought of as a market proposition that extends the traditional functionality of a product by incorporating additional services that move the emphasis towards the 'product use' rather than the 'product sale'.

With a PSS, asset ownership is not necessarily transferred to the customer. Simplistically, in the case of the photocopier (Figure 1), the producer would typically provide 'a document management solution' (see for example Xerox, www.xerox.com). Then the producer, rather than the customer, selects and provides the equipment and consumables, monitors performance, and carries out servicing and disposal. In return they receive payment as the customer uses the printing capability. A similar model is Power-by-the-Hour offered to airlines by Rolls-Royce Plc where, although the engine is sold, the service and support contract for the engine is negotiated on the basis of 'hours flown'. Indeed, while the term 'Power by the Hour' has recently entered the nomenclature of management, it was in fact coined by Bristol Sidley over 30 years ago to describe their performance-based contracts for the Viper gas turbine engines. General Electric and Pratt \& Whitney also offer performance-based contracts with commercial airlines in which their compensation is tied to product availability (i.e. hours flown). Indeed, many companies with high installed product bases (e.g., aerospace, locomotives, elevators, machine tools, business machines, printing machinery, construction equipment and agricultural machinery) all seem to be exploring such strategies. Here, the manufacturer gains from this extended relationship by learning more effectively from customers (Alonso-Rasgado et al., 2004), locking customers in to longer relationships (Vandermerwe \& Rada,1988), and reducing competition due to the difficulty in imitating services because of their intangibility and labour dependency (Oliva and Kallenberg,2003). 


\section{RESEARCH DESIGN}

The aim of this research has been to gain a deeper understanding of the issues that arise when a servitization strategy is followed by a manufacturer. Specifically, we have set out to investigate a "servitized organisation" that designs, builds and delivers integrated product and services, and to identify the challenges they are encountering in the pursuit of such a strategy. In this paper, our particular interest is product-centric servitization. This is the term we give to the phenomena where a portfolio of services is directly coupled to a product offering. In other words, an integrated product and service offering where the product itself is central to the provision of an integrated portfolio of services (e.g. maintenance, repair, and/or support). Our method has been to carryout an in-depth and multi-disciplinary case-study analysis of a UK manufacturer who gains a large proportion of its revenue from the provision of services that are closely coupled to their products. Case-based research is appropriate for exploratory and theory building research, suitable for dealing with 'how' type questions (Yin, 2003).

The choice of case company was critical to this study as we sought to investigate a manufacturer who has a track-record of achieving business success through providing a portfolio of product related services. Therefore, our case study organisation is a UK based Original Equipment Manufacturer (OEM) that designs and manufactures high value capital equipment for the power, defence and aerospace markets. For reasons of confidentiality and in order to give us greater freedom to discuss our results and findings, we refer to the company as 'ServCase'. ServCase provides capital equipment products, and often offers these with a broad range of services that ensure asset availability via a risk and revenue sharing contract. While the origin of this business dates back to the early 1990s it really only took shape in the early 2000s. This market proposition emerged in response to customers who sought to offset the cost of repair and overhaul of their products. At the same time, ServCase sought to prevent component suppliers attacking its lucrative aftermarket business. To counteract these significant threats, ServCase has initiated a series of joint ventures with organisations, based geographically locally to asset 'users' that were capable of providing maintenance and repair facilities. This is being achieved through a combination of centralised manufacture, mainly focusing on product final assembly and test, along with multiple field facilities for maintenance and repair.

A data collection protocol was developed and data was collected over a five month period, completed in September 2008. Interviews were conducted with key personnel from across the organisation such as Design Engineering, Global Component Repair, Service Innovation/ Marketing, Projects, After Market Services, Global Component Repair, Manufacturing Operations, Customer Services and Supply chain. Some 15 interviews were conducted, each carried out by 2/3 researchers from different disciplines, and typically lasting between 2 and 3 hours. For example, the manufacturing operations key personnel were interviewed by representatives from three different academic disciplines. The interviews were then coded and analysed by the same team of researchers using guidelines proposed by Miles and Huberman (1994). These results were then synthesised to aid the construction of the servitization process model, as presented in this paper, along with informing our understanding of how this impacts the host organisation.

\section{PROCESS MODEL OF PRODUCT-CENTRIC SERVITISED MANUFACTURE}


The intention of this section is to describe and explain the servitization process model. The general form of such a model is captured in Figure 2. Prior to describing how the model operates in practice, it is important to emphasise that the illustration is of a steady-state system, and does not attempt to show the interactions necessary during the creation of the overall business model (e.g. contract negotiation, product manufacture and delivery). The main 'actors' are the Customer (user), Original Equipment Manufacturer (OEM) and their partners, each of who have through-life interactions with each other and the asset in use. These interactions are illustrated by the line-arrows in the diagram. The direction of these arrows represents the 'relationship' between actors. The arrow originates from the actor who is responsible for delivering the 'action', with the head of the arrow indicating the actor who is the recipient of the benefit. For example, the OEM is shown to be responsible for the provision of maintenance and upgrades to the asset. The head of these arrows also indicates a 'touch-point' within the system. Each 'touch point' generates 'customer experiences' and can generate a 'demand signal' into the network. The principal demand signals are shown in figure 2 as block arrows, with the direction of these indicating the main feedback mechanisms within the system.

\subsection{Understanding the offering}

The starting point for explaining many process models is to describe the output from the system. In a traditional production system, the output is the physical product or capital asset (e.g.: car, boat, train). In the case of product-centric servitization the product or asset is offered with an integrated portfolio of services. There is sometimes confusion within the literature over ownership, with a common view being that OEMs are retaining ownership of products and assets rather than selling them. This is a little misleading. While the user may not necessarily own the product or asset, in most cases of product-centric servitization, ownership is transferred from the OEM to either the customer or a third party such as a financial partner. Hence, the OEM sells both the asset and a portfolio of related services. The servitization value proposition is first based on the sale of an asset (e.g. train, agricultural equipment, excavator, aircraft, machine tools, printing machinery) and then service and support of the asset in use. More sophisticated service and support offerings are sold on the basis of a 'pay-per-use' contract. Such contracts are also frequently coupled with the OEM taking a greater risk exposure if the asset fails to perform adequately. In such case, in order to mitigate the associated risk, the asset or product is designed to be capable of being 'interrogated' locally by the 'user' and OEM and/or remotely by the OEM. Such information is gathered using a combination of 'on board' modules for sensing (e.g. pressure, temperature, vibration) and communication (e.g. data-bus, internet link, wireless telemetry) (see Benedettini et al, 2009). In this way the asset is said to be 'informated'. Thus the OEM is able to collect data from, and monitor the performance of, the asset in use. The extent of the OEM's information gathering and analysis capability is a key enabler in delivering the value proposition and mitigating any risk associated with the product related services.

\subsection{The role of the OEM and its operational partners}

Fundamentally the OEM provides services to support the product in use and the customers' use of the product. Mathieu (2001) distinguishes these types as services supporting the product (SSP) and services supporting the customer (SSC).

In our process model (figure 2), the SSP that are provided by, and the responsibility of, the OEM are shown between the OEM and Asset. For example, many other services are initiated as a result of the remote 
monitoring of the asset in use. The acquisition of the data, and its subsequent analysis (usually in a bespoke operations centre), enables efficient scheduling of Maintenance and the effective provision of Repairs and Spares using new and / or re-manufactured parts. Data obtained from the asset is also used to trigger Upgrades. These provide improved functional performance. The direct recipient of all these service elements is the asset itself. The predominant variables that generate demand signals on the OEM originate from data directly from the asset. Hence, the relationship and customisation levels required to effectively and efficiently deliver these service elements are generally low. These demand signals will in turn trigger demand signals on the OEM partners.

Services supporting the customer (SSC) are shown by the arrows between the OEM and the customer, through the box labelled SSC. Here, the asset performance data is key to informing the customer about the status of the asset in use. This then enables scheduling of repair and maintenance activities, to ensure optimal availability and performance of the asset. Training and advice on the most effective and efficient use of the asset is also provided to the customer. For SCC activities, the customer's personnel (e.g. operations mangers) are the direct recipients of the services. Here, the predominant variables, that generate demand signals, originate from people (these can be both customer and OEM personnel). Hence the relationship and customisation levels, required to effectively and efficiently deliver these service elements, are generally high. These services again create demand signals from the 'user' to both the OEM and the customers partners.

\subsection{The role of the Customer and its operational partners}

The customer has the operational use of the asset, and revenue typically flows to the OEM on the basis of asset use. Operating parameters for the asset in use are agreed with the OEM and, when taken together with asset performance data, impact on the revenue received by the OEM. Our model shows the customer is responsible for the operational use of the asset, local monitoring of its performance, and providing agreed 'Low-Level Maintenance' to support the asset as it is used. These activities will generate demand signals on the customer and on its partners. The customer's operational partners work with the customer to support the asset in use by, for example, providing dynamic consumables (e.g. fuel, lubricants etc,) and other services (e.g. labour, periodic monitoring, and low level maintenance). The customer is also responsible for providing the OEM with feedback, in the form of performance monitoring data, which can also generate demand signals on the OEM and network partners.

\section{GENERATION OF KEY FINDINGS}

The purpose of the research reported in this paper has been to gain a deeper understanding of the issues that arise when a servitization strategy is followed by a manufacturer. In the section above, we have described a servitization process model. Supporting such a model places particular pressures on the manufacturer. These go beyond those traditionally associated with production operations (e.g. targets around cost, quality and delivery of the product). Quite simply, a servitized manufacturer interacts closely with customers throughout an extended life-cycle, and so has many more demand signals against which to respond (see figure 3). In this section we now describe the principal challenges that our case study company, ServCase, has experienced as it has strived to support such an integrated product and service offering. Here, it is important to emphasise, that although our findings are largely based around one case 
study, we believe that ServCase has is sufficiently advanced to provide a sound basis for exploring the characteristics of a process model in this evolving context.

\subsection{The language of services}

One of the most striking differences at ServCase is the terminology and vocabulary of the everyday language used by the employees in the process of service delivery. Whereas a conventional manufacturer's personnel use (and fully understand) terminology such as product, part and component they may only loosely understand the term service. The word 'services' usually refers to a number of offerings (e.g. maintenance, repair, insurance) and a single offering is a service. However, 'service' can also be used to refer to a level of performance (e.g. that was good service). This is only one example of many words and phrases whose semantics take on particular and specific meanings at ServCase. This distinction appears strongest amongst personnel who deal most closely with the service delivery process within the organisation. As the Services Director commented: "..to integrate with customers, we've just got to 'talk' like they do". Many people within ServCase recognise that the development of an appropriate language, based specifically around the product and service delivery, is a significant challenge. These include difficulties in describing, expressing and communicating a customer's expectations and values.

Finding 1: The language used in a servitized manufacturer is particular and peculiar; this has to be developed and adopted throughout the organisation.

Busines Supplier

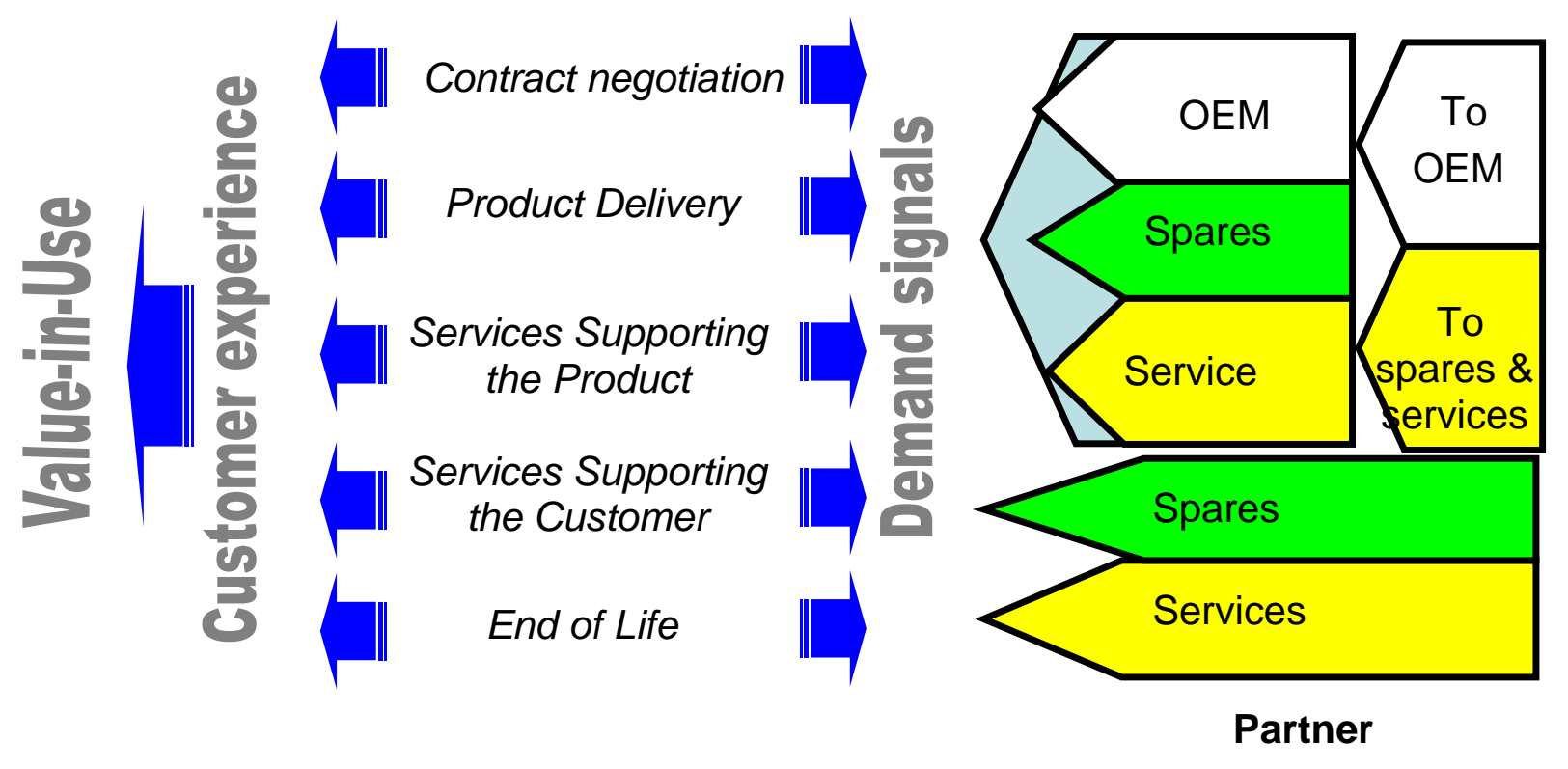

Figure 3:: Lifecycle Touchpoints and Demand Signals within a servitized manufacturer

\subsection{Value dimensions of integrated products and services}

At ServCase the nature of the relationship with the customer has changed from a transaction to that of a long-term relationship. Some broad appreciation of how value propositions differ is gained by reflecting on the business model with which each delivery system is associated. Thompson (1967) suggests that value can be created through transformation (e.g. raw material), problem solving (e.g. consulting) and mediation (e.g. banking). This complements a view that value creation can be both transactional and relational. 
Production operations tend to support a more transactional approach, whereas service operations tend to be more associated with customer relationship development. Traditional manufacturers tend to take a linear view of producing a product, which is then sold (a transaction) to the customer for their use (consumption). However, when ServCase deliver an integrated product and service offering there tends to be a series of 'touch points' between the product provider and customer. For example, initial contract negotiation may be lengthy; monitoring of the asset in-use may be carried out by the provider, which may lead to the provider servicing the product and finally the provider may take-back the product at end-of-life. Whilst the product itself may still be sold to the customer (as is the case with ServCase) the associated services are more closely associated with long-term relationships (see Verstrepen, 1988). Hence, servitization tends to combine both transactional and relationship elements into the business model. Moreover, revenue, profits and cash flow arise mainly from the relationship aspects of this model with a shift from a focus on reducing costs to improving the value-in-use for the customer. This is evident in our study with ServCase where delivering customer value was of key concern and exemplified by a Service Operations Manager when commenting that, "we as an organisation need to have a much better understanding of the value of service to a customer, rather than what we think value of a service is". Communicating and demonstrating value is also a challenge, especially with services, “... if the customer doesn't 'see' what he's getting, then he thinks he's getting nothing". This brings us to observe;

Finding 2: Value dimensions relate to both asset sale and use and therefore comprise both transactional and relationship elements; these need to be adequately defined and communicated as performance measures.

\subsection{Designing products and services}

ServCase sell their product along with a portfolio of services to assure asset availability. The design processes needed to deliver these differ to those more usually associated with product design. Traditionally, product designs are conceptualised remotely, prototyped, tested and refined, and then put into practice. With services, prototyping tends to take place through application (Levitt,1981). Here one danger is, as ServCase have found, that engineers tend to apply conventional product design processes. However, there is now an increased emphasis on the product design aspects that impact on product maintainability and reparability, which are integral to the effective and efficient delivery of the overall product-service offering. The Service Operations Director articulated this with a view that "the best thing you can do is design it [the product] knowing you're going to have 'this service' out there". ServCase has products incorporating the capability to remotely monitor their performance in the field. This incurs extra cost in product manufacture which cannot be recouped at point-of-sale, but rather relies on the customer taking-up the service contracts offered. This is typical of the many product features that are introduced to aid maintenance and servicing to support asset availability in the field.

Finding 3: Design processes need to consider both product and service features that are consistent with the delivery of through-life performance; these differ from traditional product design processes.

\subsection{Integrated delivery systems}


As with design processes, the organisational design required to support the effective and efficient delivery of through-life performance also differs. The conventional view of materials flowing into a factory, through production, to be consumed by the customer does not occur within ServCase. While a small portion of this somewhat unit-directional material flow does occur, there is a complex service delivery system that monitors and supports the asset in use superimposed upon the traditional production business. This system transcends the traditional internal / external barriers of the host business. The effective provision of an integrated product-service offering requires inter-organisational integration achieved through the coordination of manufacturing systems, maintenance systems, spare parts supply systems and logistics systems.

This delivery system is directly impacted by the relational component of the business model and associated performance measures (as outlined in section 5.2). These requirements are so particular to this context, that ServCase has decoupled this service delivery mechanism from their more conventional production system. However, they recognise that as business pressures increase the sharing of resources and knowledge will necessitate that these systems be more tightly coupled. Moreover, a tighter coupling is necessary in the supply network that supports the delivery of a product-service system. As the capital asset is provided by ServCase, and some elements of the service and support are provided by members of the supply network, effective coordination and integration between network members is essential. In practice at ServCase there have been changes in the downstream supply chain in terms of establishing joint ventures with key customers, whilst the configuration of the upstream supply chain is largely unchanged.

Finding 4: The simultaneous delivery of both products and services creates significant tensions within the operations and supply chain of the OEM; the challenge is to integrate the delivery of these such that resources and knowledge are used effectively and efficiently.

\subsection{Organisation transformation}

Transformation issues are both particular and pervasive. ServCase is an example of a manufacturer that, in the adoption of a servitization strategy, is encountering changes to language, value, along with designs of product and organisation. Throughout this case, we have been made repeatedly aware that one of the biggest challenges that ServCase are facing is the need to change from a product-oriented to a largely service-oriented business. Sections $5.1-5.3$ above summarise how, across the organisation and its broader supply chain, ServCase has and continues to change. This is emphasised by a comment from the HR Director " $\ldots$ at the interfaces between the company and the customer, I think we're seeing far more evidence of responsive agile service centred behaviour". Our study at ServCase highlighted a number of challenges, leading us to surmise that:

Finding 5: The change from traditional to servitized manufacturer requires significant organisational changes in language, values, design process and organisation design; these changes raise specific transformation issues that are unique to a move to servitization.

\section{CONCLUDING REMARKS}

Servitization is now widely recognised as the innovation of a manufacturer's capabilities and processes to move from selling products, to selling integrated product-service offerings that deliver value in use. Such a strategy is advocated as a means by which western manufactures can face-up to the challenges of competitions from lower cost economies. ServCase is one example of a UK company that has adopted a 
servitization strategy. Our work here has given us a much clearer understanding of the particular issues that are arising as ServCase attempts to deliver integrated products and services successfully. In brief, these are:

- Language used in service is particular and peculiar.

- Value dimensions are special and biased towards relationships rather transaction.

- Products and design processes are different and better enable service support.

- Integrating service and product delivery systems is challenging.

- Transformation issues are both particular and pervasive throughout customers, employees, partners and suppliers.

The work is based on data collected from a detailed case study. Whilst we believe it provides an essential platform, we recognise that our work may be limited by the use of a single, although in-depth, case study. Taking evidence from a single case does not, necessarily, imply that the findings are true of a wider set of organisations. In our case, ServCase may not yet have completed its servitization journey such that it represents an optimum solution. There is, however, little to suggest that their progress is not sufficient to inform the servitization process model that we describe in this paper.

As the process of servitization evolves, traditional manufacturing firms, with well developed capabilities in terms of products and processes will find the transition to servitized organisations a difficult one. This change perspective underpins our work where the central research question has been defined as "how do organisations innovate their capabilities and processes so that they are able to design, build and provide integrated product and service offerings that deliver value-in-use". Several sub-questions are implicit in this over-arching question:

- How are servitized organisations and product-service systems designed?

- How are servitized organisations and product-service systems built and delivered?

- How are servitized organisations and product-service systems supported by the supply network?

- How can the value-in-use delivered by product-service systems be assessed?

- How can "traditional" manufacturing firms make the transition to servitized organisations?

By addressing these questions, our aim is to produce the knowledge that enables the creation and exploitation of world-beating products and technologies, within the context of service-based competitive strategies.

\section{REFERENCE}

Aurich J \& Fuchs C, (2007), Advances in Lifecycle Engineering for Sustainable Manufacturing Businesses, Proceedings of the $14^{\text {th }} \mathrm{CIRP}$ Conference on Lifecycle Engineering, Tokyo, Japan

Alonso-RasagoT, Thompson G, Elfstrom B, (2004), 'The design of functional (total car0 products', Journal of Engineering Design, Vol 15, 6, pp515-540 
Baines T, Lightfoot H, Evans S, Neely A, Greenough R, Peppard J, Roy R, (2007) 'State-of-the-art in Product Service-Systems' Proc. IMechE Part B, Vol 221: Journal of Engineering Manufacture, 1543-1552.

Benedettini O, Baines T, Lightfoot H, Greenough R, (2009), 'State-of-the-art in Integrated Vehicle Health Management', Proc. IMechE Part G, Forthcoming.

Chase R \& Garvin D,(1989) 'The Service Factory' , Harvard Business Review, 67,4,61-69.

Chesborough, H. \& Spohrer, J., (2006), "A research manifesto for services science", Communications of the ACM, Vol. 49, No. 7, p. 35

Davies A. , (2004), "Moving base into high-value integrated solutions: a value stream approach", Industrial and Corporate Change, Vol.13, No.5, pp. 727-756

Goedkoop M, van Haler C, te Riele H,, (1999), 'Product Service-Systems, Ecological and Economic Basics', Report for Dutch Ministries of Environment (VROM) and Economic Affairs (EZ),

Hewitt P, Secretary of State for Trade and Industry, (2002;4), The Government's Manufacturig Strategy

Levitt T., (1981), "Marketing intangible products and product intangibles", Harvard Business Review, May/June, pp. $92-104$

Mathieu V., (2001), 'Service strategies within the manufacturing sector: benefits, costs and partnership', International Journal of Service Industry Management, Vol. 12, No. 5, pp. 451-475

Miles, M.B. \& Huberman, A.M. (1994) Qualitative Data Analysis: $2^{\text {nd }}$ Edition, Thousand Oaks, California: SAGE Publications.

Neely A, (2007), 'Servitization of Manufacturing' $14^{\text {th }}$ EurOMA Conf. Ankara, Turkey

Oliva R \& Kallenberg R. (2003) 'Managing the Transition from Products to Services', International Journal of Service Industry Management, 14, 2, 160-172

Slack N.. (2005), 'Operations Strategy: Will it ever realise its potential', Gestao \& Producao, 12, 3, 323-332

Vandermerwe S \& Rada J,(1988), 'Servitization of Business: Adding Value by Adding Services' European Management Journal. Volume 6, No 4, 314-32

Verstrepen S, (1999), "Servitization in the automotive sector: creating value and competitive advantage through service after sales." Global Production Management, Kluwer Publishers pp. 538 - 545.

Voss, C., Tsikriktsis, N., Frohlich, M. (2002), "Case research in operations management", International Journal of Operations and Production Management, Vol. 22, No. 2, pp. 195-219.

Wise R \& Baumgartner P. (1999), 'Go downstream: The New Profit Imperative in Manufacturing' Harvard Business Review, 77,5 133-141.

Yin, R. K. (2003) Case Study Research: Design and Methods, Third Edition. London: Sage Publications. 


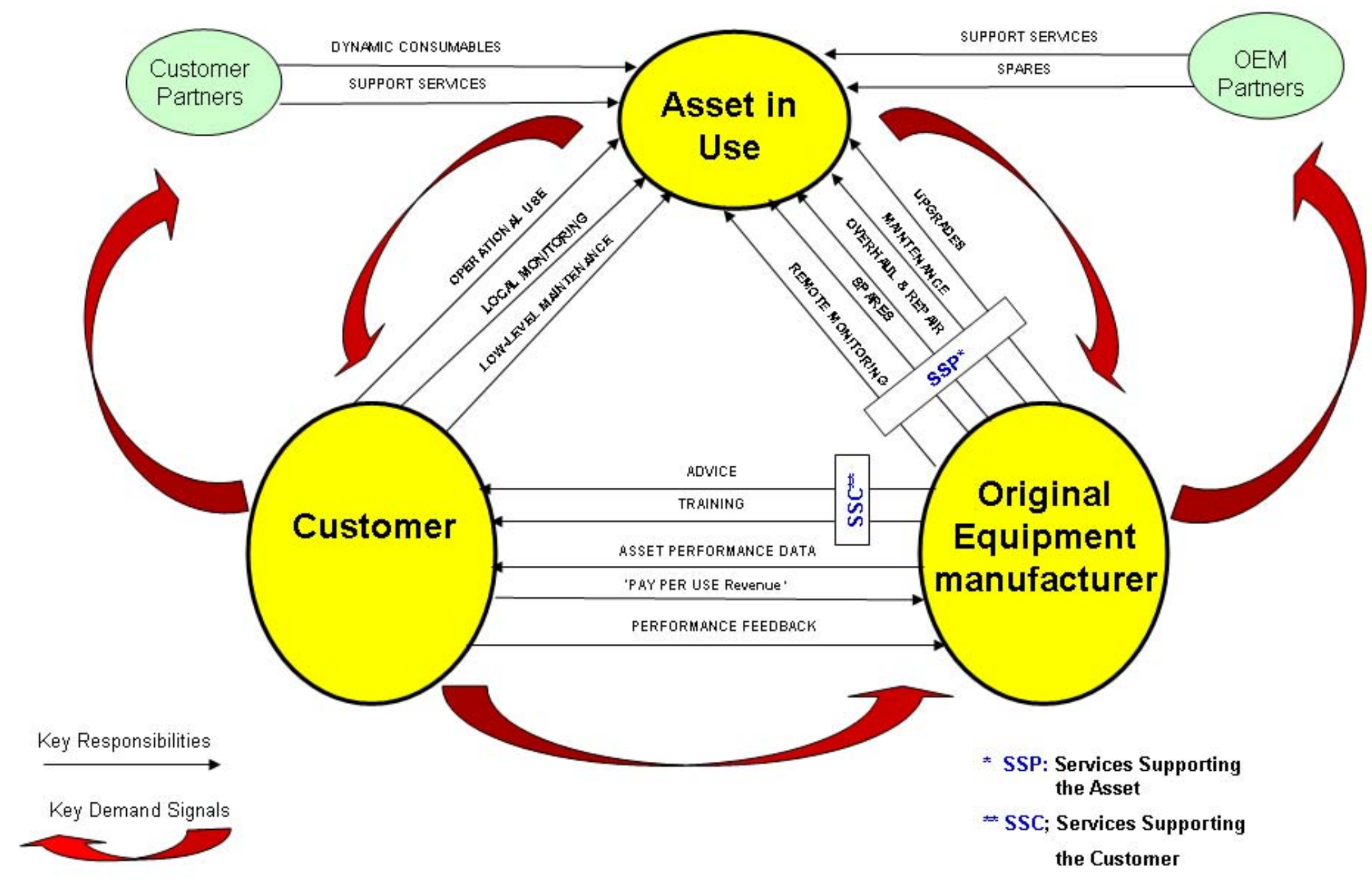

Figure 2: Senvitization process model under steadi state conditions 


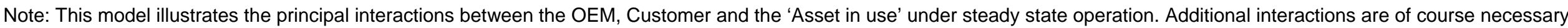
to set up the system (e.g. contracts, asset manufacture, delivery) and other interactions beyond those core to the asset use (e.g. between the customer and their partners) 